\title{
Prospecção Tecnológica dos Métodos Contraceptivos como Ferramenta de Análise da Responsabilidade Cultural na Maternidade - Os Dados a Favor da Transformação Social
}

\author{
Technological Prospection of Contraceptive Methods as an Analysis of \\ Cultural Responsibility in Maternity - The Data for Social Transformation
}

\author{
Anucha Prisco de Aguiar Peixoto ${ }^{1}$ \\ Alanna Rodrigues Santana ${ }^{1}$ \\ Kim de Vasconcelos e Araujo ${ }^{1}$ \\ ${ }^{1}$ Universidade Federal da Bahia, Salvador, BA, Brasil
}

\begin{abstract}
Resumo
O presente artigo tem como objetivo realizar uma análise dos métodos contraceptivos desenvolvidos em períodos históricos importantes do feminismo com o intuito de delinear uma trajetória das lutas e das conquistas femininas sobre a igualdade de gênero e liberdade dos corpos das mulheres, auxiliando, assim, a compreensão dos entraves e dos dilemas existentes para a superação do paradigma de exploração da maternidade atual. Para tanto, foi realizada uma pesquisa prospectiva exploratória elaborada a partir de análise de documentos de patentes no sistema Orbit Intelligence, o qual concede acesso à base de dados proprietária da FAMPAT, envolvendo publicações de patentes ao redor do mundo. Os resultados demonstraram a relação direta do desenvolvimento de métodos contraceptivos com as exigências dos movimentos feministas. Ainda se observou que a sociedade responsabiliza bastante as mulheres pela contracepção, visto que o número de pedidos de patentes de métodos contraceptivos femininos é superior aos masculinos nos recortes históricos utilizados.
\end{abstract}

Palavras-chave: Contraceptivos. Prospecção. Feminismo.

\begin{abstract}
This article aims to analyze the contraceptive methods developed in important historical periods of feminism in order to outline a trajectory of women's struggles and achievements on gender equality and freedom of women's bodies, thus helping to understand the obstacles and existing dilemmas for overcoming the current maternity exploitation paradigm. To this end, an exploratory prospective research was conducted based on patent document analysis in the Orbit Intelligence system, which grants access to FAMPAT's proprietary database, involving patent publications from around the world. The results demonstrated the direct relationship between the development of contraceptive methods and the demands of feminist movements. And it has been noted that society holds women very responsible for contraception, since the number of patent applications for female contraceptive methods is higher than for men in the historical cuts used.
\end{abstract}

Keywords: Contraceptive. Prospection. Feminism.

Área Tecnológica: Tecnologia Social. 


\section{Introdução}

Negreiros (2018), ao escrever sobre a vida das mulheres no cangaço ${ }^{1}$, relata como era a maternidade para as cangaceiras, que, por conta da vida errante e violenta que levavam, não criavam seus filhos nem desenvolviam laços de afetividade com os bebês, pois eles eram doados poucos dias após nascidos. Segundo a autora, a maternidade era um acidente de percurso indesejado por todos. Aleksiévitch (2016) traz nos relatos de mulheres que combateram as tropas nazistas alemãs uma concepção de reprodução a serviço da guerra e aponta que é comum nos depoimentos o prazer de gerar um filho capaz de servir numa batalha. Observa-se, assim, que a concepção de uma gestação possui diferentes motivações e implicações para as pessoas, a depender do momento histórico-econômico, do tipo de civilização e do espaço geográfico em que estão inseridas.

A exemplo disso, Federici (2017) afirma que durante o século XVII, na ilha de Barbados, os proprietários das plantations ${ }^{2}$ tentavam controlar a reprodução das escravas de acordo com a necessidade de trabalho nos campos. A autora afirma ainda que, na Europa, nesse mesmo período, houve a instituição da pena de morte para as mulheres que usassem métodos contraceptivos por cauda das transformações de ordem econômica que a sociedade europeia estava vivendo com o início do capitalismo, que tem como base a exploração da mão de obra humana.

Durante o processo de colonização da América, os europeus se impressionaram com a "imoralidade" dos indígenas que possuíam uma visão de sociedade mais coletiva, em que não existiam núcleos familiares com regras sociais de pertencimento e de propriedade uns sobre os outros. Federici (2017) ilustra esse choque de culturas, retirado de um trecho do diário do padre jesuíta Paul Le Jeune de meados do século XVII:

Eu disse-lhe que não era honrável para uma mulher amar a qualquer um que não fosse seu marido e que, com este mal pairando, ele não poderia ter certeza de que o filho era realmente seu. Ele respondeu: "Não tens juízo. Vocês franceses amam apenas a seus filhos, mas nós amamos a todos os filhos da nossa tribo". Comecei a rir, vendo que ele filosofava como os cavalos ou as mulas. (FEDERICI, 2017, p. 222)

No Brasil atual, a visão da reprodução está alinhada a uma ideia de família tradicional fomentada historicamente pela cultura europeia católica, em que a linhagem bem protegida de uma família garante a acumulação de bens por muitas gerações em um mesmo núcleo familiar. Para a manutenção dessa célula familiar fechada, Kollontai (1979, p. 74) afirma que foi criado o ideário de matrimônio burguês que possui dois princípios falsos: a indissolubilidade e o conceito de propriedade da posse absoluta de cônjuges por outro que, atrelada à desigualdade entre os sexos, se configura como uma armadilha emocional e física para as mulheres, pois se imagina que ao homem basta, para escapar da solidão moral que o rodeia, o amor e exigir seus direitos sobre a outra pessoa. Kollontai (1979, p. 48-49) conclui, ainda, que:

\footnotetext{
${ }^{1}$ Cangaço foi um movimento social relacionado ao banditismo ocorrido no Nordeste brasileiro durante os séculos XIX e XX, no qual grupos de nômades armados viviam cometendo crimes violentos, desafiando as autoridades e espalhando terror nas cidades por onde passavam.

${ }^{2}$ Plantation é um tipo de sistema agrícola baseado em uma monocultura de exportação mediante a utilização de latifúndios e mão de obra escrava. Foi muito utilizado na colonização da América que mais tarde foi levada para a África e a Ásia.
} 
A idéia da propriedade inviolável do esposo foi cultivada com todo esmero pelo código moral da classe burguesa, com a sua família individualista encerrada em si mesma, construída totalmente sobre as bases da propriedade privada. A burguesia conseguiu com perfeição inocular essa ideia na psicologia humana.

Para tal controle sobre os corpos e as mentes femininas, foi delineado na construção do patriarcado, também, o papel da mulher na sociedade e na família. A elas, foi designado o trabalho doméstico e filial, romantizando o seu papel de tutora emocional do casamento, administradora do lar e detentora do cuidado com os filhos. Dessa forma, desconfigurou-se o caráter de trabalho que possui todas essas funções, não havendo remuneração ou sequer reconhecimento sobre essa lida, como se fosse próprio do gênero feminino as características necessárias para tal labor. Erasmo Carlos (1981), cantor e compositor brasileiro traduz bem esse espírito de exploração abusivo e romantizado por meio da letra de uma de suas músicas:

Dizem que a mulher é o sexo frágil

Mas que mentira absurda!

Eu que faço parte da rotina de uma delas

Sei que a força está com elas

Vejam como é forte a que eu conheço

Sua sapiência não tem preço

Satisfaz meu ego, se fingindo submissa

Mas no fundo me enfeitiça

Quando eu chego em casa à noitinha

Quero uma mulher só minha

Mas pra quem deu luz não tem mais jeito

Porque um filho quer seu peito

O outro já reclama a sua mão

E o outro quer o amor que ela tiver

Quatro homens dependentes e carentes

Da força da mulher

Mulher! Mulher!

Do barro de que você foi gerada

Me veio inspiração

Pra decantar você nessa canção

Mulher! Mulher!

Na escola em que você foi ensinada

Jamais tirei um 10

Sou forte, mas não chego aos seus pés. 
Diante desse cenário, a ideia da concepção de um filho em grande parte das comunidades atuais existe dentro dessa relação de abuso de toda uma sociedade com os corpos das mulheres. $\mathrm{O}$ arquétipo social ${ }^{3}$ da mãe pessoal ${ }^{4}$ amorosa possui características por diversas vezes sobre-humanas, como explica Jung (2000, p. 93);

[...] que não é apenas da mãe pessoal que provêm todas as influências sobre a psique infantil descritas na literatura, mas é muito mais o arquétipo projetado na mãe que outorga à mesma um caráter mitológico e com isso lhe confere autoridade e até mesmo numinosidade.

Como consequência dessa construção de ideário materno, há a ciência servindo a essa dinâmica de forma parcial, se configurando como o que Althusser (1980) caracterizou de "Aparelho Ideológico do Estado", sendo esta uma importante ferramenta de análise sociocultural. Além disso, a ciência está para a modernidade como a igreja esteve no período medieval, é ela que dita verdades e determina tendências de comportamentos em todos os âmbitos da vida, possuindo um caráter político e econômico central em suas dinâmicas.

[...] quanto mais "técnica" é considerada uma questão, menos espaço abre para o levantamento de questões políticas substantivas, tais como as perguntas sobre "o tipo de sociedade em que queremos viver" e o lugar da ciência nesta sociedade, ou sobre como devem ser estabelecidas, no caso da ciência e da tecnologia, as fronteiras entre a cura e o melhoramento, a eugenia "positiva" e a "negativa", a utopia e a distopia. (MITRE, 2016, p. 16)

Em concordância com essa perspectiva, Edgar Morin (2002) afirma que a Ciência não é imparcial em seus estudos e conclusões e que está subordinada a estruturas de poder que são resultantes das relações socioeconômicas das comunidades. Dessa forma, ao analisar os caminhos percorridos pela Ciência, não se pode perder de vista a leitura da cultura que circunda os sujeitos, sendo necessário o questionamento sobre as estruturas ideológicas e o seu enraizamento sociocultural.

Portanto, é possível encontrar na ciência muitos aspectos que desnudam essa cultura de responsabilização exclusiva da mãe sobre os filhos. Assim, o presente artigo busca, avaliar a trajetória histórica de depósitos de patentes relativos a contraceptivos, relacionando o ressurgimento e o desenvolvimento dessa tecnologia com a trajetória de lutas e de conquistas femininas em períodos históricos importantes do feminismo sob a luz dos debates sobre a igualdade de gênero e a liberdade dos corpos das mulheres, com o intuito de auxiliar a compreensão dos entraves e dos dilemas existentes para a superação do paradigma materno atual.

\footnotetext{
${ }^{3} \mathrm{Na}$ psicologia analítica, criada por Carl Gustav Jung, o conceito de arquétipo se refere às imagens primitivas inseridas no inconsciente coletivo desde os primórdios do ser humano. São moldes inerentes ao ser desde o princípio da existência, os quais têm a função de atuar como fonte primordial para o amadurecimento da mente. Informação disponível em: https://www.infoescola.com/psicologia/arquetipos/.

${ }^{4}$ Jung reconhece que existem múltiplas representações do materno: "Como todo arquétipo, o materno também possui uma variedade incalculável de aspectos Menciono apenas algumas das formas mais características: a própria mãe e a avó; a madrasta e a sogra; uma mulher qualquer com a qual nos relacionamos; no sentido da transferência mais elevada, a deusa, especialmente a mãe de Deus, a Virgem [...]" (JUNG, 2000, p. 91-92), porém trata-se neste artigo da mãe pessoal, a que dá à luz.
} 


\section{Metodologia}

Trata-se de uma pesquisa prospectiva exploratória elaborada a partir de análise de documentos de patentes no sistema Orbit Intelligence, o qual concede acesso à base de dados proprietária da FAMPAT, envolvendo publicações de patentes em todos os segmentos tecnológicos.

A pesquisa utilizou como palavras-chave, nos campos de busca título e resumo, os termos: method of contraception +, contraception method+, contraceptive method+, contraception product + , associadas entre si por meio do conector booleano AND. Para refinamento da pesquisa, foram analisados documentos de patentes segundo a Classificação de Internacional de Patentes (CIP) (International Patent Classification - IPC) e a Cooperative Patent Classification (CPC), na área de abrangência $\mathrm{A} 61 \mathrm{~K}$, que se refere a preparações para finalidades médicas.

A estratégia inicial de pesquisa teve como objetivo mapear as patentes de contraceptivos, identificando os principais países depositantes e as tecnologias relacionadas nesse segmento nos períodos históricos importantes do movimento feminista compreendidos entre o fim do século XIX até meados do século XX (primeira onda); de 1950 a 1990 (segunda onda); a partir dos anos de 1990 até 2011 (terceira onda) e, por fim, de 2012 até os dias atuais (a quarta onda). Uma onda feminista compreende um momento histórico em que pautas com características específicas se tornaram predominantes entre as mulheres.

Os resultados obtidos foram analisados e discutidos com base no levantamento de bibliografia relacionada ao tema, como artigos científicos, reportagens e textos extraídos de livros e encontrados em sites cujas temáticas são correlatas com a pesquisa.

\subsection{O Contexto Histórico dos Métodos Contraceptivos}

Antes de adentrar nos resultados da pesquisa, cabe uma contextualização histórica dos métodos contraceptivos. Afinal, a história da concepção carrega consigo uma parte da ancestralidade feminina importante relacionada ao poder de gerar outro ser humano e a posição social da mulher.

Cabe salientar que os métodos contraceptivos não são um advento da ciência moderna. Federici (2017) afirma que, no período pré-capitalista, as mulheres eram detentoras e guardiãs milenares do mistério da concepção, sabendo como evitar a gravidez e também como interrompê-la. Esse conhecimento era passado de geração em geração de mulheres a milênios, possibilitando uma liberdade maior sobre os seus corpos e um posicionamento social de mais igualdade com relação aos homens do que se presencia na contemporaneidade.

Com o surgimento de uma nova ordem econômica, baseada na exploração da mão de obra, esse conhecimento foi brutalmente arrancado das mãos femininas. Federici (2017, p. 155) aponta que durante os séculos XVI e XVII "[...] um desejo quase fanático por aumentar a população predominou em todos os países durante o período em que o mercantilismo esteve em seu apogeu [...]", pois passou-se a compreender que a maior riqueza de um estado era a capacidade de exploração numerosa dos corpos de seus cidadãos. Afinal, de que adiantaria a descoberta das minas de ouro nas Américas se o estado não tivesse com quem explorá-las? Como 
consequência dessa política econômica, surgiram os registros demográficos, recenseamentos e a formalização da própria demografia como a primeira "ciência do Estado".

Dentro desse contexto, as mulheres eram detentoras de uma poderosa força econômica; a capacidade de gerar trabalhadores. Foi, então, que começaram a ser acusadas de bruxaria $e$, por meio da queima de centenas de milhares de mulheres na fogueira, por um período de aproximadamente 400 anos, a caça às bruxas transformou os métodos contraceptivos que as mulheres utilizavam em instrumentos diabólicos.

Segundo Federici (2017, p. 324): "As acusações de perversão sexual e infanticídio contra as bruxas tinham um papel central e estavam acompanhadas pela virtual demonização das práticas contraceptivas [...]".

Dessa maneira, por meio do massacre de mulheres, institucionalizou-se o controle do Estado sobre o corpo feminino. Federici (2019) afirma que os contraceptivos desapareceram no século XVII, existindo apenas na clandestinidade entre as prostitutas e quando ressurgiram no seio da sociedade já estavam sob o domínio da ciência e sua utilização condicionada à permissão dos homens dentro do casamento.

Assim, compreender as questões relacionadas aos debates feministas atuais perpassa diretamente sobre o fenômeno do controle da reprodutividade pelo Estado, que tem a ciência como principal ferramenta de monopólio de conhecimento a respeito do tema. Esse controle do saber, associado ao terror imposto durante a queima das bruxas, reconfigurou as estruturas sociais de todo o mundo, se transformando em um fator central para o posicionamento desfavorável das mulheres na sociedade contemporânea.

\section{Resultados e Discussão}

Kollontai (1979) explica que, nas sociedades pré-industriais europeias, ameríndias e de matrizes africanas, existia uma divisão de trabalho que proporcionava às mulheres um maior contato umas com as outras, visto que a vida das comunidades era organizada de uma maneira coletiva. Com o advento do capitalismo e a reestruturação da divisão do trabalho e da família, que destinou às mulheres o trabalho doméstico e confinou-as em seus lares, houve um afastamento feminino da vida coletiva e, consequentemente, uma das outras. $\mathrm{O}$ código de ética e moral afirmava que lugar de mulher "correta" era em casa cuidando dos filhos, do marido e do lar.

$\mathrm{O}$ avanço do capitalismo no fim do século XIX que demandou mais força de trabalho nas fábricas, junto com a Primeira e Segunda Guerra Mundial em meados do século XX que levavam parte dos homens à guerra, fez as mulheres saírem de seus lares, passando a assumir postos de trabalho nas indústrias e o comando financeiro das famílias. Assim, é nesse reencontro com suas companheiras no mercado de trabalho que as mulheres voltam a se organizar em grupo para a reivindicação de seus direitos, iniciando, então, a Primeira Onda do Feminismo. Kollontai (1979, p. 17) descreve esse período assim:

Ao arrancar do lar, do berço, milhares de mulheres, o capitalismo converte essas mulheres submissas e passivas, escravas obedientes dos maridos, num exército que luta pelos seus próprios direitos e pelos direitos e interesses da comunidade humana. Desperta o espírito de protesto e educa [à] vontade. 
Franchini (2017) menciona que nesse período as reivindicações estavam ligadas a direitos básicos trabalhistas e de cidadania, assim, a primeira onda surgiu então com o objetivo de exigir, principalmente, o direito de votar. Suffragettes ou Sufragistas, em português, era o nome das mulheres que iniciaram o movimento a favor da concessão do voto feminino. No Brasil, em 24 de fevereiro de 1932 foi garantido o sufrágio feminino. Os direitos reprodutivos não foram foco nos movimentos da Primeira Onda e também, como consequência, não foram encontrados no ORBIT registros de pedidos de patentes de métodos contraceptivos.

A Segunda Onda (1950 a 1990) do Feminismo surge então após as grandes Guerras impulsionadas pelo movimento existente em torno dos Direitos Civis, como demonstra Beauvoir (2019), quando ela desmonta as questões de gênero e traz à tona os debates relacionados à família, ao mercado de trabalho, às desigualdades de fato e as legais, à sexualidade e aos direitos reprodutivos. Neste período o movimento Contracultura surgiu forte, com os os beatniks, punks e hippies contestando os valores morais da época e abrindo espaço para a desconstrução dos papéis da família e das pessoas nas famílias. Sobre o movimento feminista nesse período, Franchini (2017) explica,

Foi nessa época que foram iniciados uma série de estudos focados na condição da mulher, onde começou-se a construir uma teoria-base, uma teoria raiz sobre a opressão feminina. Muito por isso, geralmente, quando nos referimos ao feminismo de segunda onda, costumamos querer dizer mais especificamente do que chamamos de feminismo radical (de raiz) [...] pois toda a movimentação feminista daquela época foi pautada na teoria radical que versa sobre a nossa condição de exploradas por conta do nosso sexo e das nossas funções reprodutivas. Isso pautou as discussões da segunda onda que se caracterizou por uma fase de luta por direitos reprodutivos e discussões acerca da sexualidade.

De acordo com Jon Guillebaud (1985), a contracepção hormonal foi criada nos Estados Unidos, na década de 1960, após as reivindicações da Segunda Onda do Feminismo. O quarteto responsável pela descoberta foi Margareth Sanger (1879-1966), enfermeira e ativista pelos direitos das mulheres à contracepção; Katherine McCormick (1875-1967) (ARIE et al., 2009, p. 7), bióloga e feminista milionária que financiou o projeto e idealizou o desenvolvimento de uma pílula anticoncepcional barata e acessível com o objetivo de impedir a gravidez em mulheres sadias, e, principalmente, em função de motivos eugênicos, e, por fim; o biólogo Gregory Pincus (1903-1967) e o ginecologista John Rock (1890-1984), ambos da universidade de Harvard nos EUA.

Aqui nota-se a tecnologia correspondendo às demandas dos movimentos culturais. Em uma prospecção tecnológica dos métodos contraceptivos referentes a esse período, encontra-se uma crescente indicação de pedidos de patentes. No Gráfico 1 observa-se que de 1950 a 1960 não houve nenhum pedido, pois era ainda o início das reivindicações, a sociedade estava sendo impactada com o novo paradigma proposto pelos movimentos. 
Gráfico 1 - Período da Segunda Onda do Movimento Feminista

1850 a 1960

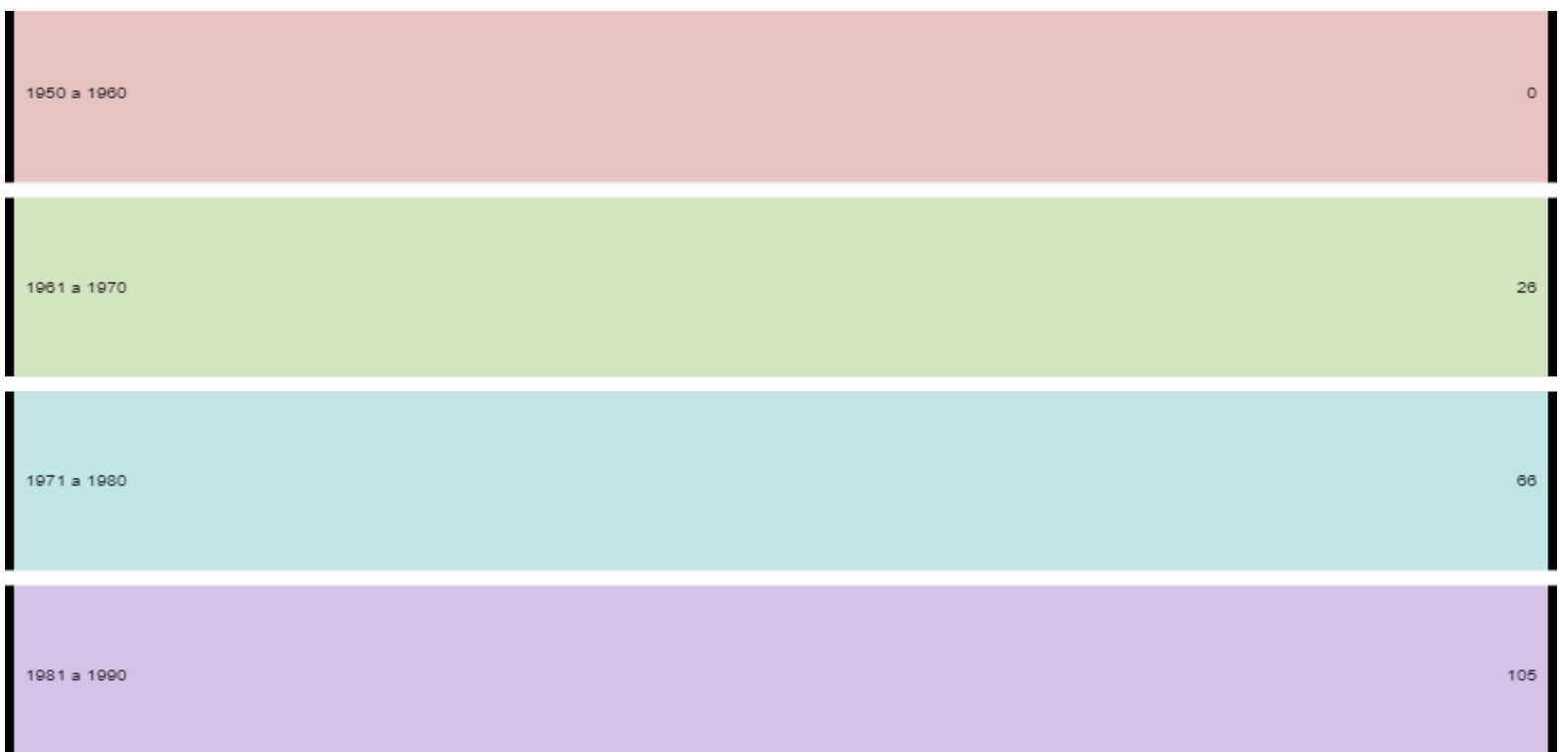

Fonte: Elaborado pelos autores deste artigo (2019)

A ativista e jornalista Barbara Seaman (1969) denunciou riscos, alguns deles fatais, das altas doses de hormônios dos primeiros anticoncepcionais, a exemplo de coágulos, câncer, ataque cardíaco, derrame, depressão e diminuição da libido. Embasado na pesquisa de Seaman, o senador americano Gaylord Nelson (1916-2005) convocou algumas audiências públicas, em 1970, no intuito de investigar se os efeitos relatados pelas mulheres estavam relacionados à pílula e questionar se a indústria farmacêutica sabia desses riscos e não os informava às consumidoras. Entretanto, apenas homens foram convocados a testemunhar sobre a segurança da pílula, mesmo com o protesto das "Women's Libertation Movement" que exigiam ser ouvidas, conforme fora noticiado à época pelo jornal Chicago Daily Tribune.

Outro aspecto a ser considerado é que o surgimento da pílula anticoncepcional, associada às demandas exigidas pelo movimento feminista da época, proporcionou o início das políticas de planejamento familiar. No Brasil, de acordo com o Manual do Planejamento Familiar do Ministério da Saúde, em 1984 foi implantado o Programa de Assistência Integral à Saúde da Mulher (PAISM), que incluiu seis elementos: escolha livre de métodos, informação para usuárias, competência técnica, relação usuária-serviço; acompanhamento de usuárias e integração do planejamento familiar ao atendimento em saúde reprodutiva. Em 1996, um projeto de lei foi aprovado pelo Congresso Nacional e sancionado pela Presidência da República, o qual regulamentou o planejamento familiar por meio da Lei n. 9.263/1996.

Durante a Segunda Onda, o foco não foi o papel dos homens na sociedade, mas os direitos das mulheres. Dessa forma, apesar de as mulheres alcançarem avanços sobre o controle da concepção, a subjugação da mulher ao homem ainda era sistêmica. A exemplo disso, a lei 4.121, de 27 de agosto de 1962, que alterou alguns artigos do Código Civil de 1916, afirmava que, ao marido, era deferida a chefia da sociedade conjugal e, portanto, se uma esposa tomasse a pílula sem o seu consentimento, ele poderia pedir a anulação do casamento (antes de completar dois anos).

Como consequência disso, no Gráfico 2 observa-se a proporção dos pedidos de registro de patentes de métodos contraceptivos para homens e mulheres, apenas $1 \%$ dos pedidos foram 
para o público masculino. Esse dado demonstra a relação direta do desenvolvimento da ciência atrelado as demandas socioculturais.

Gráfico 2 - Proporção de depósitos de patentes na Segunda Onda do Movimento Feminista Segunda Onda

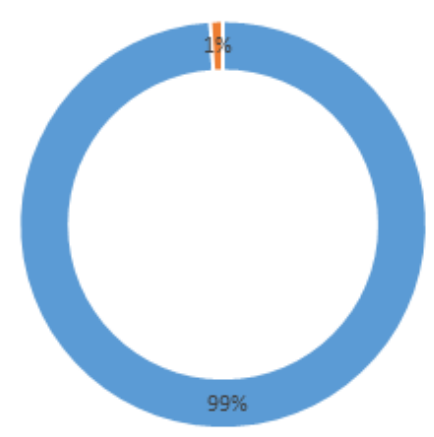

- Muheres = Homens

Fonte: Elaborado pelos autores deste artigo (2019)

A Terceira Onda (1990 a 2010) surgiu junto com movimentos punks femininos que tratavam de assuntos como estupro, patriarcado, sexualidade e o empoderamento feminino $e$ reivindicavam a quebra da universalização do conceito de mulher, admitindo a variedade de possibilidades e as vivências do "ser mulher".

Dentro da visão plural da mulher, reivindicada pela Terceira Onda, surgiu o conceito de interseccionalidade em 1989, introduzido pela jurista negra Kimberlé Creenshaw, como uma ferramenta para o entendimento amplo das questões relacionadas ao feminismo negro, visto que as mulheres negras são atingidas por diferentes tipos de opressão, como gênero, raça, classe, sexualidade, etc. Carla Akotirene (2018, p. 27) define e comenta a importância dessa ferramenta para o entendimento do feminismo negro:

É uma ferramenta teórica e metodológica usada para pensar a inseparabilidade estrutural do racismo, capitalismo e [cis-heteropatriarcado], e as articulações decorrentes daí, que imbricadas repetidas vezes colocam as mulheres negras mais expostas e vulneráveis aos trânsitos destas estruturas. Infelizmente agora sofre os perigos do esvaziamento, pois caiu no gosto acadêmico das branquitudes. Fala-se muito de feminismo interseccional sem trabalhar o paradigma afrocêntrico, de forma desconexa da origem, fundamento e propostas epistemológicas das feministas negras.

Durante 1975 e 1979 houve uma queda nas vendas de anticoncepcionais ocasionada por uma forte campanha sobre os riscos das pílulas à saúde. Após esse ocorrido, Kemmeren, Algra e Grobbee (2001) informam que durante a década de 1980 uma nova geração de anticoncepcionais com redução na concentração dos componentes e com formulações próximas ao hormônio natural surgiu. O mercado dos anticoncepcionais voltou então a se movimentar, e os pedidos de patentes de métodos contraceptivos aumentaram 76,2\% em 20 anos. Observa-se esse crescimento vertiginoso no Gráfico 3. 
Gráfico 3 - Período da Terceira Onda do Movimento Feminista

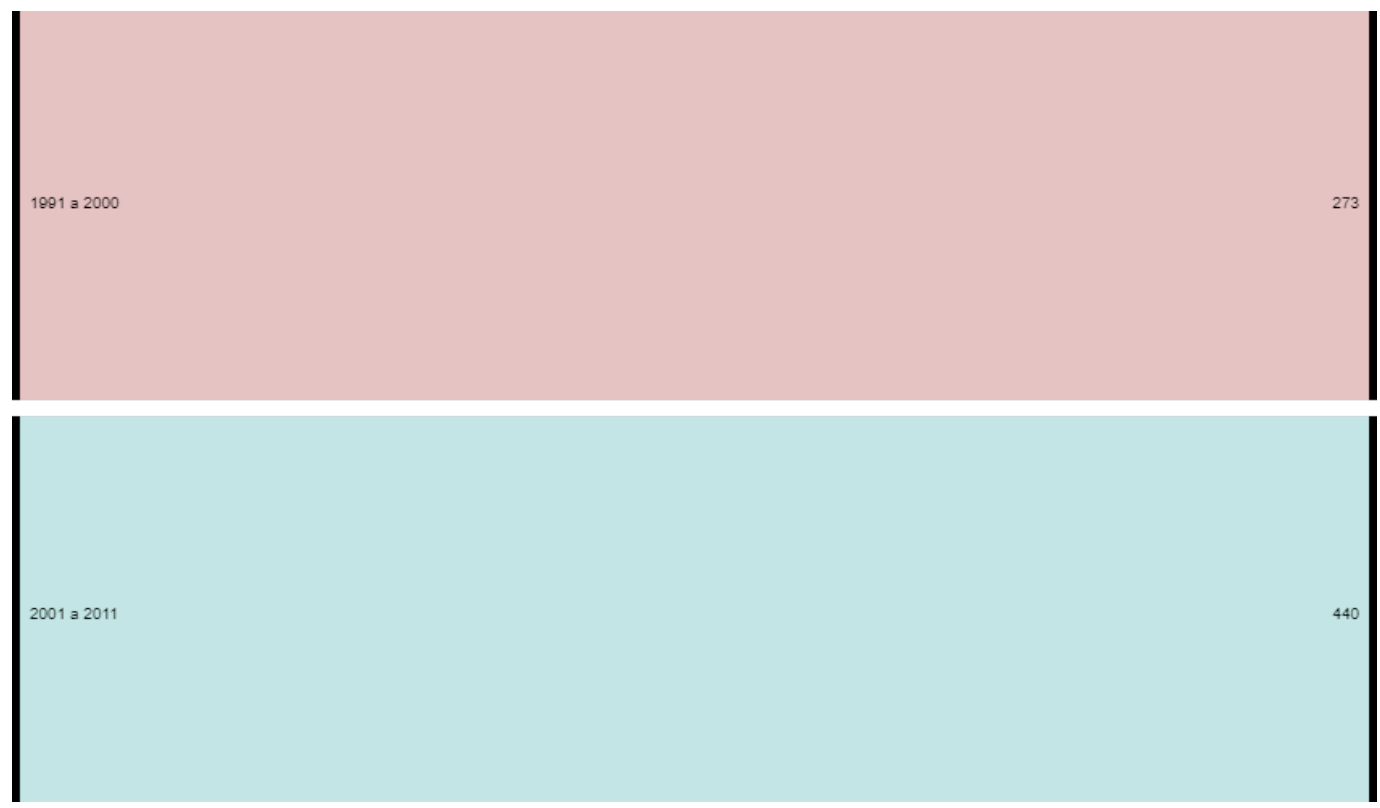

Fonte: Elaborado pelos autores deste artigo (2019)

Na Terceira Onda, os debates sobre a masculinidade como uma construção social a ser repensada começaram a surgir. Dessa vez, não apenas a desconstrução das mulheres foi evocada, mas também a dos homens, para que houvesse mais espaço para as mulheres em diversos âmbitos sociais. Silva (2000) descreve a crise de identidade da masculinidade contemporânea, cujos debates em torno do machismo, sexismo e homofobia trouxeram à tona o questionamento dos estereótipos masculinos relacionados à agressividade, à violência e à rigidez emocional. No Brasil, em 22 de setembro de 2006, foi criada a Lei Maria da Penha, que tornou mais rigorosa a punição para agressões contra a mulher quando ocorridas no âmbito doméstico e familiar.

Apesar dos avanços nos debates, a responsabilidade dos homens sobre a paternidade e a sua responsabilidade na concepção e na contracepção de um filho avançou pouco. O Gráfico 4 demonstra que, apesar de ocorrer durante esse período um aumento exponencial dos pedidos de patentes de contraceptivos, o aumento de solicitações direcionados a pílulas para homens foi quase insignificante em relação ao Gráfico 2.

Gráfico 4 - Proporção de depósitos de patentes na Terceira Onda do Movimento Feminista

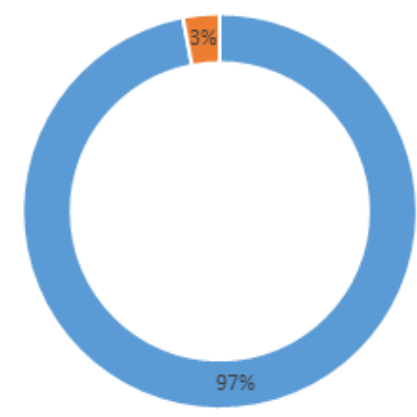

Fonte: Elaborado pelos autores deste artigo (2019) 
Em 2008, um estudo conduzido para a aplicação de um anticoncepcional masculino injetável ${ }^{5}$, com parte do financiamento das Nações Unidas, em todo o mundo, contou com a participação de 320 homens entre 18 e 45 anos, segundo o bioquímico Douglas Colvard (2016). A injeção, aplicada a cada oito semanas, se mostrou eficaz. Ocorre que, de acordo com Colvard (2016), a Organização Mundial da Saúde, em 2016, determinou a interrupção da pesquisa devido aos efeitos colaterais, como espinhas, mudança de humor, dores musculares e alteração da libido ${ }^{6}$.

A Quarta Onda (2012 até os dias atuais) está acontecendo agora e é marcada pelo uso das redes sociais para disseminação de informações e organização dos movimentos. Franchini (2017) afirma que pautas como a cultura do estupro, a representação da mulher na mídia e o assédio nos ambientes corporativos vêm à tona $e$ o patriarcado começa a ser enfrentado dentro de uma dinâmica também econômica e ecológica, agregando uma característica anticapitalista e sustentável ao movimento.

A compreensão do patriarcado ${ }^{7}$ como um sistema político que gera opressão, exploração e desigualdades tornou-se o centro dos debates. Cypriano (2013) afirma que é necessário entender o patriarcado como "o sistema", não é um sistema a mais, não é um produto do capitalismo, não é consequência da colonização, não é uma forma de racismo, mas sim o sistema de todas as opressões, todas as discriminações e de todas as violências. Surge, então, um feminismo ecológico, anticapitalista e antirracista que se une com os diversos movimentos sociais, pois compreende que todas as desigualdades provêm do patriarcado.

Com o intuito de se contrapor e se desvincular do patriarcado, as feministas atuais reinvocam a interação com a natureza e o conhecimento sobre o próprio corpo. Surgem, então, movimentos de ginecologia natural que enaltecem o empoderamento, a autonomia e o protagonismo das mulheres, que vêm se recusando a se medicarem com pílulas anticoncepcionais, uma vez que estão sadias.

Dessa forma, observa-se nesse período uma queda nos pedidos de registro de patentes de métodos contraceptivos, como demonstra a Figura 5:

Gráfico 5 - Período da Quarta Onda do Movimento Feminista

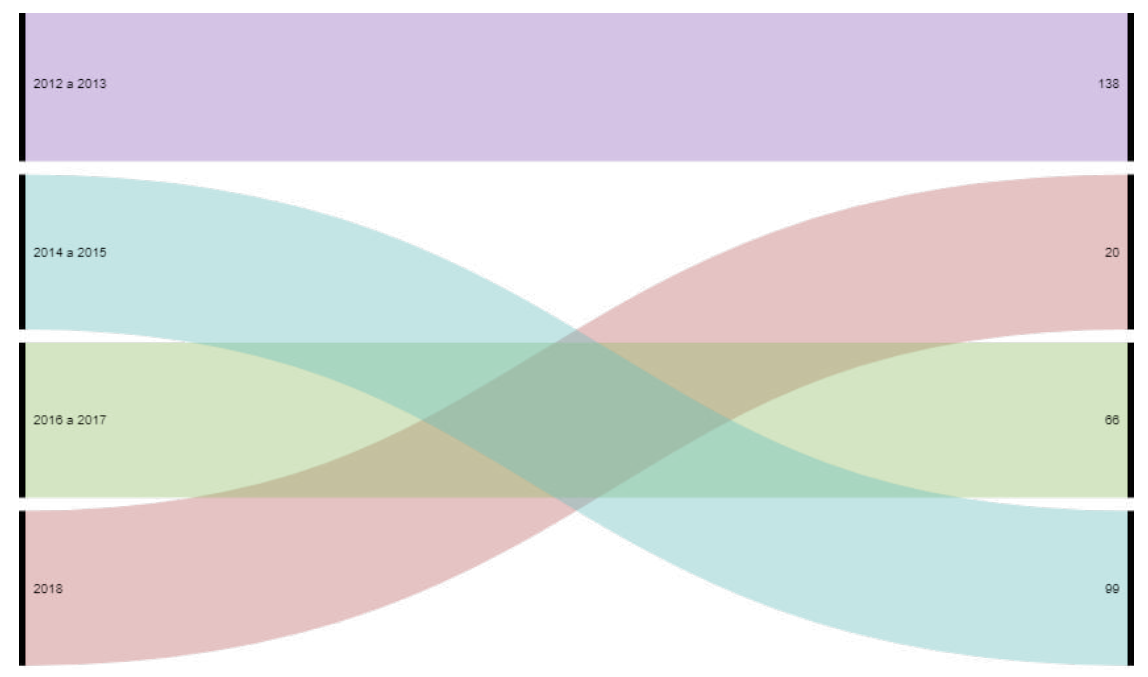

Fonte: Elaborado pelos autores deste artigo (2019)

\footnotetext{
${ }^{5} \mathrm{O}$ estudo foi realizado pelo Centro de Pesquisa e Desenvolvimento de Contracepção, situado na Virginia (EUA).

${ }^{6}$ Decisão tomada pelo Painel de Revisão de Projetos de Pesquisa do Departamento de Saúde Reprodutiva e Investigação da Organização Mundial da Saúde (OMS).

${ }^{7} \mathrm{O}$ patriarcado designa uma formação política, econômica e social em que os homens detêm o poder (DELPHY, 2009).
} 
A razão para a volta do debate em torno da pílula atualmente não se restringe ao aspecto da saúde, mas também pela partilha de responsabilidade sobre a contracepção e a concepção com os homens. A sociedade ainda não se articula para que homens e mulheres possam assumir de maneira justa e equilibrada seus papéis na sociedade, como exemplo disso, apresenta-se a Figura 6, que demonstra a diferença entre os pedidos de patentes de métodos contraceptivos para homens e mulheres na atualidade.

Gráfico 6 - Proporção de depósitos de patentes na Quarta Onda do Movimento Feminista Quarta Onda

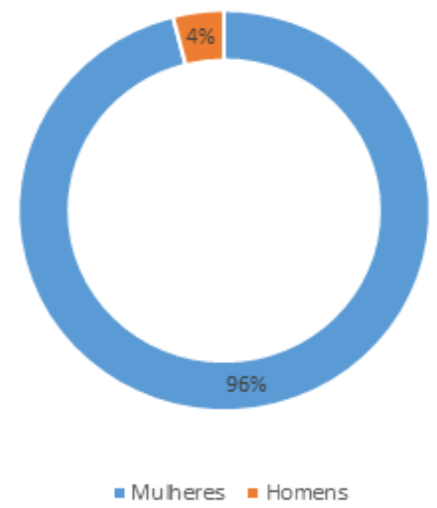

Fonte: Elaborado pelos autores deste artigo (2019)

Assim, como foi possível observar nas análises dos gráficos anteriores, a ciência e a tecnologia respondem às demandas, $e$ às pressões sociais, pois a falta de desenvolvimento de tecnologias que possibilitem a inserção dos homens na incumbência no controle da reprodução como agente responsável direto e não apenas gerencial aponta para uma fraca compreensão desse papel.

\section{Considerações Finais}

A pesquisa demonstrou uma relação próxima entre os pedidos de patentes e o apelo popular nos períodos estudados. Acompanhando o avanço do capitalismo e a mudança das relações sociais, as mulheres iniciaram sua luta por direitos e igualdade de gênero no começo do século $\mathrm{XX}$, mas ainda não especificamente voltados para a reprodução, o que prova a ausência de pedidos de patentes relacionados ao tema. Já a partir da década de 1950, com forte apelo popular, as mulheres passaram a se organizar e a exigir mais controle sobre seus corpos e, assim, pedidos de patentes de métodos contraceptivos começaram a aparecer no mundo. Essa relação paralela pode ser vista no decorrer de toda a história do movimento feminista.

É elucidativo perceber os artifícios utilizados pela ciência operada pelo sistema patriarcal e capitalista para responder às demandas populares com a exploração dos corpos femininos. O número inexpressivo de pedidos de patentes de métodos contraceptivos voltados aos homens prova essa façanha. Em todas as ondas do feminismo relacionadas ao avanço da ciência e da tecnologia, os pedidos dos métodos contraceptivos para mulheres superam a marca de $96 \%$ comparado aos dos homens. Assim, o sistema consegue operar de modo ainda desigual em relação aos gêneros para manutenção de uma cadeia exploratória e mercantilista. 
Porém, é encorajador notar que, mesmo de uma maneira propositalmente deturpada, os avanços científicos têm que responder às demandas sociais necessárias ao convívio social pacífico. A luta por direitos sociais é, em certo grau, a força motriz que pode transformar a sociedade para um maior aproveitamento da liberdade individual e satisfação coletiva, principalmente por meio da ciência e da tecnologia.

\section{Referências}

AKOTIRENE, Carla. O que é interseccionalidade? Belo Horizonte: Letramento, 2018a. (Coleção Feminismos Plurais)

AKOTIRENE, Carla. 2018 começa com mais um brutal caso de feminicídio. [2018b].

Disponível em: https://www.geledes.org.br/o-que-e interseccionalidade/2018. Acesso em: 2 abr. 2019.

ALEKSIÉVITCH, S. A guerra não tem rosto de mulher. 9. ed. São Paulo: Companhia das Letras, 2016.

ALTHUSSER, L. Ideologia e aparelhos ideológicos de Estado. 3. ed. Lisboa: Editorial Presença/ Martins Fontes, 1980.

ARIE, Wilson M. Y. et al. História da anticoncepção. São Paulo: Leitura Médica, 2009.

BEAUVOIR, Simone de. O segundo sexo: a experiência vivida. 5. ed. Rio de Janeiro: Nova Fronteira, 2019.

BRASIL. Assistência em planejamento familiar: manual técnico. 4. ed. Brasília: Secretaria de Política de Saúde, Ministério da Saúde, 2002.

BRASIL. Lei n. 4.121, de 27 de agosto de 1962. Dispõe sobre a situação jurídica da mulher casada. Brasília, DF, 27 de agosto de 1962. Disponível em: http://www.planalto.gov.br/ccivil_03/leis/ 19279.htm. Acesso em: 2 jun. 2019.

BRASIL. Lei n. 9.279, de 14 de maio de 1996. Dispõe sobre regulação de direitos e obrigações relativos à Propriedade Industrial. Brasília, DF, 14 de maio de 1996. Disponível em: http://www. planalto.gov.br/ccivil_03/leis/19279.htm. Acesso em: 2 jun. 2019.

CARLOS, Erasmo. Mulher. Rio de Janeiro: Polydor, 1981.

CFM - CONSELHO FEDERAL DE MEDICINA. Código de Ética Médica. 1988. Disponível em: https://portal.cfm.org.br/index.php?option =com_content\&view= category\&id $=10 \& I t e m i d=123$. Acesso em: 2 jun. 2019.

COLVARD, Douglas. Autor de estudo com contraceptivo masculino explica polêmica. Entrevista concedida a Karolina Bergamo. Revista Saúde, [s.l.], 2016. Disponível em: https://saude.abril.com. br/medicina/autor-de-estudo-com-contraceptivo-masculino-explica-polemica/. Acesso em: 2 jun. 2019.

CYPRIANO, Breno. Construções do pensamento feminista latino-americano. Rev. Estud. Fem., Florianópolis, v. 21, n. 1, p. 11-39, abril de 2013. Disponível em http://www.scielo.br/scielo. php?script=sci_arttext\&pid=S0104-026X2013000100002\&lng =en\&nrm =iso. Acesso em: 13 maio 2020. 
DELPHY, Christine. Patriarcado (teorias do). In: HIRATA, H. et al. (org.). Dicionário Crítico do Feminismo. Editora UNESP: São Paulo, 2009. p. 173-178.

FEDERICI, Silvia. O calibã e a bruxa, mulheres, corpo e acumulação primitiva. São Paulo: Editora Elefante. 2017.

FEDERICI, Silvia. O ponto zero da revolução: trabalho doméstico, reprodução e luta feminista. São Paulo: Editora Elefante, 2019.

FRANCHINI, B. S. O que são as ondas do feminismo? Revista QG Feminista, [s.l.], 2017. Disponível em: https://medium.com/qg-feminista/o-que-s\%C3\%A3o-as-ondas-dofeminismoeeed092dae3a. Acesso em: 2 jul. 2019.

GUILLEBAUD. Jon. Contraception: Your Questions Answered. [s.l.]: Churchill Livingstone, 1985.

JUNG, Carl Gustav. Os arquétipos e o inconsciente coletivo. Tradução Maria Luíza Appy, Dora Mariana R. Ferreira da Silva. Petrópolis, RJ: Vozes, 2000.

KEMMEREN, J. M.; ALGRA, A.; GROBBEE, D. E. Third generation oral contraceptives and risk of venous thrombosis: meta-analysis. Br Med J., [s.l.], 2001. Disponível em: https://www.bmj.com/ content/bmj/323/7305/131.full.pdf. Acesso em: 2 jun. 2019.

KOLLONTAI, Alexandra. A nova mulher e a moral sexual. 2. ed. [s.l.]: Global, 1979.

MITRE, Maya. As relações entre ciência e política, especialização e democracia: a trajetória de um debate em aberto. 2016. Disponível em: http://www.scielo.br/pdf/ea/v30n87/0103-4014ea-30-87-00279.pdf. Acesso em: 2 jun. 2019.

MORIN, Edgar. Ciência com Consciência. Rio de Janeiro: Bertrand Brasil, 2002.

NEGREIROS, Adriana. Maria Bonita: Sexo, violência e mulheres no cangaço. 1. ed. Rio de Janeiro: Objetiva, 2018.

ORBIT INTELLIGENCE. [2019]. Disponível em: www.orbit.com. Acesso em: 2 jun. 2019.

ONU - ORGANIZAÇÃO DAS NAÇÕES UNIDAS. Conferências Mundiais da Mulher. [2019].

Disponível em: http://www.onumulheres.org.br/planeta5050-2030/conferencias/. Acesso em: 2 jun. 2019.

SEAMAN, Barbara. The doctor's case against the pill. [s.l.]: Hunter House, 1969.

SILVA, Sergio Gomes da. Masculinidade na história: uma construção cultural da diferença entre os sexos. Psicol. Cienc. Prof., Brasília, v. 20, n. 3, p. 8-15, setembro de 2000. Disponível em: http://www.scielo.br/scielo.php?script=sci_arttext\&pid=S1414$98932000000300003 \& \operatorname{lng}=e n \& n r m=$ iso. Acesso em: 12 maio $20 \overline{20}$.

\section{Sobre os Autores}

\section{Anucha Prisco de Aguiar Peixoto}

E-mail: anucha_prisco@hotmail.com

Graduado em Pedagogia pela Universidade do Estado da Bahia.

Endereço profissional: Rua Polidoro Bittencourt, Escola Estadual Luiz Tarquinio CPM, Boa Viajem, Salvador, BA. CEP: 41218-700. 


\section{Alanna Rodrigues Santana}

E-mail: lannars@gmail.com

Pós-Graduada Lato Sensu em Direito do Estado pela Universidade Federal da Bahia.

Endereço profissional: Avenida Ulisses Guimarães, Multicab Empresarial, n. 3.386, Salvador, BA. CEP: 41219-400.

\section{Kim de Vasconcelos e Araujo}

E-mail: kimdevasconcelos@yahoo.com.br

Mestre em Propriedade Intelectual e Transferência Tecnologia para Inovação.

Endereço profissional: Avenida Orlando Gomes, n. 1.296, Piatã, Salvador BA. CEP: 41613-036. 